\title{
FITOTERAPIA NO CONTROLE DO Rhipicephalus (boophilus) microplus, AGENTE CAUSADOR DA DOENÇA “TRISTEZA PARASITÁRIA”: UMA REVISÃO DE LITERATURA
}

\author{
PHYTOTHERAPY IN THE CONTROL OF Rhipicephalus (boophilus) microplus, THE CAUS- \\ ATIVE AGENT OF THE "PARASITIC SADNESS" DISEASE: A LITERATURE REVIEW \\ FITOTERAPIA EN EL CONTROL DE Rhipicephalus (boophilus) microplus, EL AGENTE \\ CAUSANTE DE LA "TRISTEZA PARASÍTICA": UNA REVISIÓN DE LA LITERATURA
}

\author{
Fernanda Cáceres Siqueira ${ }^{1}$ \\ Rodrigo Machado Pereira ${ }^{2}$ \\ Luiz Francisley de Paiva ${ }^{3}$
}

RESUMO: Os Rhipicephalus (boophilus) microplus, carrapatos bovinos são hematófagos e vetores de agentes patogênicos (bactéria Anaplasma marginale e protozoários do gênero Babesia sp.) aos animais e seres humanos. São ectoparasitos causadores de prejuízos econômicos na produção de leite, na produção de carne e mortalidade dos animais. Os bovinos sofrem com reações alérgicas, estresse, ferimentos causados no couro e por outras doenças relacionadas. A perda de peso e a diminuição leiteira das matrizes podem ocorrer devido ao agravo ocasionado. A doença Tristeza Parasitária correlaciona duas patogenias a Babesiose e a Anaplasmose. A resistência destes vetores para a Tristeza Parasitária nos rebanhos se deu, devido ao uso abusivo de acaricidas no tratamento químico. Este tratamento além de não ser garantia de cura aos bovinos, seu efeito agride os animais e o meio ambiente através de resíduos deixados. Os fitoterápicos utilizados como carrapaticidas oferecem menores danos aos animais e ao meio ambiente. Os fitoterápicos: Óleo de Neen (Azadirachta indica), Citronela de Java (Cymbopogon winterianus) e Citronela de Ceilão

\footnotetext{
I' Graduada Bacharel em Nutrição, pela Universidade do Vale do Sapucaí (2013), atualmente Pós graduanda no Curso de Microbiologia Aplicada pela Universidade do Vale do Sapucaí. Atua na profissão de Nutricionista em Qualidade dos Alimentos; visando normas sanitárias e boas práticas de fabricação.

${ }^{2}$ Mestrado em Biociências Aplicadas à Saúde (2016) pela Universidade Federal de Alfenas (Alfenas - MG). Graduação em Ciências Biológicas (2012) e especialização em Análises Clínicas (2015) pela Universidade do Vale do Sapucaí (Pouso Alegre - MG). Atualmente, é coordenador do curso de Ciências Biológicas da UNIVÁS. Também coordena cursos de pós-graduação lato sensu nas áreas de ciências biológicas e da saúde. Membro do Comitê de Ética no Uso de Animais (CEUA) e responsável pelos laboratórios de Histotecnologia e Microscopia do LMB I. Tem atuado nas áreas de morfologia, biologia experimental, biologia celular e molecular, com os seguintes temas: biologia da célula tumoral, atividade antiproliferativa, ciclo celular, citotoxicidade, genotoxicidade, mecanismos moleculares de proliferação, produtos naturais e histotecnologia.

${ }^{3}$ Mestrado profissional em Ciências Aplicadas à Saúde (2019) pela Universidade do Vale do Sapucaí. Graduação em Ciências Biológicas pela Universidade do Vale do Sapucaí (2012) e especialista em Análises Clínicas (2015) pela Universidade do Vale do Sapucaí. Tem experiência em microbiologia com ênfase em microbiologia clínica, ambiental e de alimentos. Atualmente é docente do curso de bacharelado em Nutrição e Ciências Biológicas pela Universidade do Vale do Sapucaí. Também é pesquisador técnico do Laboratório de Pesquisas Básicas da Universidade do Vale do Sapucaí. Trabalha com susceptibilidade aos antimicrobianos com ênfase em óleos essenciais e extrato vegetal, biofilmes e fatores patogênicos associados à Candida SPP.
} 
(Cymbopogon nardus L.), Hortelã ou Mentha piperita, Eucalipto (Eucalyptus spp.), Extrato de Jenipapo (Genipa americana), Alho orgânico (Allium sativum L.), Fumo em corda (Nicotiana tabacum), Melaleuca alternifólia, apresentaram um controle eficiente aos parasitos e repeliram também, outras doenças oportunistas recorrentes. Além de contribuírem para a saúde dos bovinos, bem como para a preservação do meio ambiente, e um impacto econômico de menor custo aos criadores. O objetivo deste trabalho é salientar o efeito dos fitoterápicos sobre essa classe de agentes patogênicos causadores da Tristeza Parasitária em Bovinos.

Palavras-chave: Fitoterápicos. Rhipicephalus. Babesiose. Anaplasmose.

ABSTRACT: Rhipicephalus (boophilus) microplus, bovine ticks, are hematophagous and vectors of pathogens (Anaplasma marginale bacteria and Babesia sp. protozoa) to animals and humans. They are ectoparasites that cause economic losses in milk production, meat production and animal mortality. Cattle suffer from allergic reactions, stress, wounds to the leather and other related diseases. The loss of weight and the reduction of milk in the dams can occur due to the damage caused. The Parasitic Tristeza disease correlates two pathogens, Babesiosis and Anaplasmosis. The resistance of these vectors to Parasitic Sadness in herds was due to the abusive use of acaricides in chemical treatment. This treatment, in addition to not being a guarantee of cure for cattle, its effect harms animals and the environment through the leftovers. Herbal medicines used as ticks offer less damage to animals and the environment. Herbal medicines: Neen oil (Azadirachta indica), Java citronella (Cymbopogon winterianus) and Ceylon citronella (Cymbopogon nardus L.), Mint or Mentha piperita, Eucalyptus (Eucalyptus spp.), Jenipapo extract (Genipa americana), Garlic Organic (Allium sativum L.), Rope tobacco (Nicotiana tabacum), Melaleuca alternifolia, presented an efficient control to the parasites and also repelled other recurrent opportunistic diseases. In addition to contributing to the health of cattle, as well as to the preservation of the environment, and a lower cost economic impact for the breeders. The aim of this work is to highlight the effect of herbal medicines on this class of pathogens that cause Parasitic Sadness in Cattle.

Keywords: Herbal Medicines. Rhipicephalus. Babesiosis. Anaplasmosis.

RESUMEN: Rhipicephalus (boophilus) microplus, garrapatas bovinas, son hematófagas y vectores de patógenos (bacterias Anaplasma marginale y protozoos del género Babesia sp.) Para animales y humanos. Son ectoparásitos que provocan pérdidas económicas en la producción de leche, producción de carne y mortalidad animal. El ganado vacuno sufre reacciones alérgicas, estrés, heridas en el cuero y otras enfermedades relacionadas. La pérdida de peso y la reducción de leche en las presas puede ocurrir debido al daño causado. La enfermedad parasitaria de Tristeza correlaciona dos patógenos, Babesiosis y Anaplasmosis. La resistencia de estos vectores a la Tristeza Parasitaria en los rebaños se debió al uso abusivo de acaricidas en el tratamiento químico. Este tratamiento, además de no ser garantía de cura para el ganado, su efecto perjudica a los animales y al medio ambiente a través de las sobras. Las medicinas a base de hierbas utilizadas como garrapatas ofrecen menos daño a los animales y al medio ambiente. Hierbas medicinales: aceite de Ne-en (Azadirachta indica), citronela de Java (Cymbopogon winterianus) y citronela de Ceilán (Cymbopogon nardus L.), menta o Mentha piperita, eucalipto (Eucalyptus spp.), Extracto de jenipapo 
(Genipa americana), ajo orgánico ( Allium sativum L.), tabaco de cuerda (Nicotiana tabacum), Melaleuca alternifolia, presentó un control eficiente a los parásitos y también repelió otras enfermedades oportunistas recurrentes. Además de contribuir a la salud del ganado, así como a la preservación del medio ambiente, y un impacto económico a menor costo para los ganaderos. El objetivo de este trabajo es resaltar el efecto de las medicinas a base de hierbas sobre esta clase de patógenos que causan Tristeza Parasitaria en el Bovino.

Palabras-clave: Medicamentos a base de hierbas. Rhipicephalus. Babesiosis. Anaplasmosis.

\section{INTRODUÇÃO}

Os carrapatos são considerados importantes vetores de agentes patogênicos para animais e seres humanos. Por serem hematófagos adaptam-se a resposta imune do hospedeiro; afetam a saúde dos animais em geral e devido a sua capacidade de transmissão patogênica por longos períodos de parasitismo, garantem seu desenvolvimento (SCHOOL et al, 2016).

Nativos da Ásia, sua amplificação ocorreu devido às viagens de embarcações citadas na literatura, com a transição de animais e artigos de compra e venda (KESLLER, 1998). Há relatos de sua representação em um sepulcro I.50o A.C no antigo Egito (MORAIS et al, 2013). Situa-se atualmente Ásia, Austrália, México, América Central, América do Sul e África (KESLLER, 1998).

No Brasil foram catalogadas 66 espécies de ectoparasitas, sendo 45 da família Ixodidae e 2i da família Argasidae (BASTOS et al, 2016).

Causadores de infestações em bovinos leiteiros se desenvolvem no Brasil praticamente o ano todo, devido ao clima tropical favorável (NEPOMOCENO et al, 2018).

Estes parasitos pertencem ao Filo Arthropoda, Classe Aracnida, Ordem Parasitiforme, Família Ixodidae e Gênero Boophilus (MORAIS et al, 2013).

Para a pecuária brasileira o Rhipicephalus (Boophilus) microplus é um ectoparasito considerável (CRUZ; 2017), devido aos prejuízos econômicos que somam mais de três bilhões de dólares anuais nos requisitos de queda na produção de leite, carne e mortalidade dos animais (SANTOS et al, 2018).

Os carrapatos ocasionam ferimentos no couro dos animais, seguidos de reações alérgicas e estresse. Comprometem o desenvolvimento de bezerros com a perda de peso. Em matrizes ocorre a diminuição da produção leiteira, e em ambos os casos devido ao 
agravo de outras doenças por ser transmissor de agentes patogênicos, pode ocorrer a morte do animal (BISPO et al, 2020).

A bactéria Anaplasma marginale e protozoários do gênero Babesia sp., transmitem aos bovinos a Tristeza Parasitária Bovina, (TURETA et al, 2020).

O uso abusivo de acaricidas em rebanhos promoveu a resistência destes vetores, contudo há a necessidade da busca por novas tecnologias a partir de extratos vegetais que apresentem menor resistência por parte dos carrapatos, menor efeito residual na carne e no leite dos animais (BISPO et al, 2020).

O objetivo deste trabalho é salientar o efeito dos fitoterápicos sobre essa classe de agentes patogênicos causadores da Tristeza Parasitária em Bovinos.

\section{METODOLOGIA}

Este estudo foi baseado em artigos publicados em bases eletrônicas de dados disponíveis na mídia virtual, por conterem um acervo fidedigno e de amplo aspecto.

\section{REVISÃO DE LITERATURA}

\section{TRISTEZA PARASITARIA}

A Tristeza Parasitária é causada por um conjunto de agentes patológicos, transmitidos pelos ectoparasitas (carrapatos) que acometem bovinos e bubalinos. Apresenta sintomatologia e epidemiologia similares que correlacionam duas patogenias a Babesiose e a Anaplasmose (SILVA et al, 202I).

O principal vetor biológico é o Rhipicephalus (Boophilus) microplus porém outra forma de transmissão ocorre pelo contato com insetos hematófagos e ou substâncias, objetos que estiveram em contato com sangue contaminado (SANTOS et al, 2017).

A Babesiose bovina refere-se ao gênero Babesia, ao filo Apicomplexa, classe Piroplasma, ordem Piroplasmida e família Babesiidae, são protozoários que parasitam os eritrócitos e podem infectar também outras classes de animais e seres humanos. As espécies que infectam bovinos são: Babesia bigemina, Babesia bovis, Babesia divergens e Babesia major (MENDES, 2019). 
A Anaplasmose refere-se ao gênero Anaplasma, ao filo Proteobacteria, classe Alphaproteobacteria, ordem Rickettsiales, família Anaplasmataceae e Rickettsiaceae, são bactérias

gram negativas que acometem os eritrócitos. A espécie Anaplasma marginale é mais patogênica aos bovinos. Também existem a Anaplasma centrale, utilizada na fabricação de vacinas; Anaplasmose ovis e Anaplasmose phagocytophilum (SILVA et al, 202I).

Os sinais clínicos em bovinos de ambas patologias podem se apresentar como: anorexia, tremores, taquicardia, taquipneia, redução dos movimentos ruminais, prostração, redução da lactação, anemia, icterícia, hemoglobinúria, acometimento da coordenação motora, agressividade e morte (BAHIA et al, 2020).

O diagnóstico se faz através de métodos diretos com esfregaço sanguíneo com a observação dos protozoários, capa leucoplaquetária e esfregaço de orelha (ALMEIDA et al, 2019).

O tratamento ocorre com a administração de medicamentos antiparasitário (dipropionato de imidocarb), anti-histaminicos, analgésicos, antibióticos e outros suplementos (SILVA et al, 202I).

A vacinação é uma forma de prevenção assim como o controle de vetores (SILVA et al, 2021).

A utilização de produtos químicos para controlar a infestação de carrapatos, além de causar uma alta resistência do parasito, ocasiona prejuízos em relação a qualidade da carne e leite produzidos pelos animais e avarias ao meio ambiente. Devido a necessidade de um manejo mais natural e menos agressivo, a utilização de fitoterápicos como carrapaticidas é um método seguro de aplicação para os animais e para o meio ambiente (SEBOLD et al, 2017).

\section{FITOTERÁPICOS UTILIZADOS NO CONTROLE DO RHIPICEPHALUS (BO- OPHILUS) MICROPLUS CAUSADOR DA TRISTEZA PARASITÁRIA ÓLEO DE NEEN (AZADIRACHTA INDICA)}

O Neem (Azadirachta indica) pertence à família Meliaceae (PAES et al, 2015), foi inserido no Brasil através de sementes pelo Instituto Agronômico do Paraná - IAPAR, no ano de 1986 para estudos da ação inseticida desta planta. De origem indiana apresenta-se em 
forma de árvore onde pode ser utilizada para construção ou sombreamento (BATISTA et al, 2016).

Pesquisas botânicas apontam o Neem com ação antimicrobiana e alta ação antiparasitária carrapaticida com menor efeito residual. Sua apresentação é oleosa e sua aplicação ocorre através da pulverização no animal bovino. Seu efeito de controle dos ectoparasitos é eficiente (SEBOLD et al, 2017) (BATISTA et al, 2017) e não oferece toxicidade às pessoas, aos animais e ao meio ambiente (COELHO et al, 2019).

\section{CITRONELA DE JAVA (CYMBOPOGON WINTERIANUS) E CITRONELA DE CEILÃO (CYMBOPOGON NARDUS L.)}

Essas plantas medicinais apresentam mais de roo espécies em áreas tropicais, pertencem a família Poaceae (RAUBER et al, 2020), suas características sensoriais são de aromas cítricos, frutais e refrescantes, sua composição oleosa atua na ação repelente larvicida e suas propriedades químicas apresentam controle na infestação de carrapatos (AVILA et al, 2020).

\section{HORTELÃ OU MENTHA PIPERITA}

A hortelã ou Mentha são cultivadas em diversas regiões por serem plantas de fácil adaptação geográfica, originadas da Europa pertencem a família Lamiaceae, são reconhecidas pelo forte aroma e por suas propriedades medicinais (FIGUEIREDO et al; 2016).

O óleo destas herbáceas mostrou-se eficiente carrapaticida, cultivado como um híbrido no mundo todo, possui também efeitos anti-sépticos, antibacteriano, fungicida, antiespasmódico (PROENÇA, 2018).

\section{EUCALIPTO (EUCALYPTUS SPP.)}

O Eucalipto possui características aromáticas marcantes próprias de cada espécie; pertence à família Myrtaceae; é cultivado no mundo todo com algumas espécies hibridas. Reconhecido farmacologicamente com efeito antibacteriano, fungicida, acaricida e outros (JAIME, 2019).

O extrato hidroalcóolico e o óleo de eucalipto puro possuem ação repelente e inseticida no combate aos artrópodes bovinos, sua ação pode ocorrer na fase de ovoposição bem como na fase larval (OLIVEIRA et al, 2017) (GALLI et al, 2018). 


\section{EXTRATO DE JENIPAPO (GENIPA AMERICANA)}

O Jenipapo possui grande importância no meio econômico por ser utilizado na produção de bebidas e alimentos. Seu efeito acaricida é bem semelhante aos efeitos dos organofosforados e carbamatos comercializados. Pertencente à família Rubiaceae pode colaborar significativamente com a conservação do meio ambiente sem causar danos por não proporcionar resíduos tóxicos como os produtos convencionais (BISPO et al, 2020).

\section{ALHO ORGÂNICO (ALLIUM SATIVUM L.)}

O alho é um condimento muito utilizado no mundo todo, originário da Ásia pertence à família Liliaceae, foi inserido na nutrição animal através da medicina veterinária (AVILA et al, 2020).

Apresenta importante ação acaricida, repelente e anti- parasitário. A oferta é realizada aos bovinos a uma concentração entre i a $2 \%$, acrescido de ração ou concentrado mineralizado (SILVEIRA et al, 2014).

\section{FUMO EM CORDA (NICOTIANA TABACUM)}

O fumo em corda (Nicotiana tabacum) pertence à família das Solanáceas, utilizado desde 1690 como inseticida biológico na Inglaterra, foi difundido pelo mundo com função promissora de combate e controle de parasitas (SILVA et al, 2017); utilizado no combate aos parasitas dos bovinos é um tipo de fotoquímico muito eficiente. Aplicado em forma de extrato age no controle de parasitos e parasitoses recorrentes nos animais (SILVEIRA et al, 2014) (SILVA, 2018).

\section{MELALEUCA ALTERNIFÓLIA}

A Melaleuca alternifólia pertence à família Myrtaceae, é originária da Austrália e está associada a 230 espécies, atualmente é cultivada no Brasil com produção de matéria prima limitada, sendo o óleo muito utilizado em bovinos no controle carrapaticida ( $\mathrm{Ne}$ pomoceno et al, 2020).

Suas formulações compreendem efeitos larvicida, repelente, aromática, inseticida, antimicrobiana, biocida e antifúngica (ASSIS et al, 2020). 


\section{CONSIDERAÇÕES FINAIS}

$\mathrm{Na}$ literatura podemos observar vários estudos sobre a ação positiva dos fitoterápicos sobre o controle dos carrapatos, e assim foi possível anular a evolução dos agentes patogênicos causadores da Tristeza Parasitária.

Os fitoterápicos contribuem para a saúde dos bovinos, bem como para a preservação do meio ambiente impactando em um menor custo aos criadores.

Novos estudos em busca de descobertas sobre o tema serão necessários, uma vez que a natureza é ampla e parte dela ainda desconhecida.

\section{REFERÊNCIAS}

ALMEIDA, L.S de; SENA, L.M; BARIONI, G.; MORAES, T.M.A; OLIVEIRA, R. E de. Comparação entre métodos de avaliação direta do diagnóstico da babesiose em bovinos. Pesquisa, Sociedade e Desenvolvimento, [S. 1.], v. 8, n. Io, pág. e328101388, 2019. DOI: $\begin{array}{lllll}\text { I0.33448 } & \text { rsd-v8iro.1388. Disponível em: }\end{array}$ https://rsdjournal.org/index.php/rsd/article/view/1388. Acesso em 30/II/202I.

AVILA, L. M.; CHAGAS, J. D. R.; MARTINS, M. R. S.; MACHADO, K. A.; MARQUES, T. L. P.; MORAES, R. F. F.; BAÊTA, B. A.; ROIER, E. C. R. Principais fitoterápicos utilizados no controle de ectoparasitas e endoparasitas de equinos e bovinos. Research, Society and Development, v. 9, n. II, e359119503, 2020. (CC BY 4.0) | ISSN 25253409. Disponível em: https://rsdjournal.org/index.php/rsd/article/download/9503/8503/131693 . Acesso em $30 /$ II $/ 2021$.

ASSIS, K. M. A. ; REGO, R. I. A .; MELO, D. F.; SILVA, L. M .; OSHIRO, J.; JOÃO A .; FORMIGA， F. R .; PIRES, V. C.; LIMA, A. A. N.; CONVERTI, A.; DAMASCENO, B. P. G. L. Potencial terapêutico do óleo essencial de Melaleuca alternifolia em novos siste 
mas de administração de medicamentos. Current Pharmaceutical Design, Volume 26, Número $\quad 33, \quad 2020, \quad$ pp. 4048-4055 (8). Disponível em: https://doi.org/I0.2174/138161282666620030512404I . Acesso em 30/II/2021.

BASTOS, T. S. A.; MADRID; D. M. C.; FARIA, A. M. FREITAS, T. M. S.; LINHARES, G. F. C. Carrapatos em animais silvestres do bioma cerrado triados pelo cetas, IBAMA-Goiás. Ciênc. anim. bras., Goiânia, v. 17, n. 2, p. 296-302,2016. Disponível em: http://dx.doi.org/10.1590/1089-6891vi7i236239. Acesso em 30/II/2021.

BATISTA, M. C.; G, V. F. Controle de ectoparasitas em bovinos de corte com óleo de Neem. Edição Especial, p. I84 -192. 2016. ISSN 2175-2214. Disponível em: https://www.fag.edu.br/upload/revista/cultivando_o_saber/5854616f59593.pdf Acesso em $30 /$ II $/ 2021$.

BATISTA, F. T.; LACERDA, G. D.; SILVA, J. R. S.; RODRIGUES, L. P. T.; FEITOSA, T. P.; MUSTAFA, V. S. O uso de plantas medicinais na medicina veterinária - Riscos e Benefícios. Revista Científica do Curso de Medicina Veterinária - FACIPLAC.;

Brasília - DF, v.4, n. 2, 2017.; ISSN: 2448-457I. Disponível em: http://revista.faciplac.edu.br/index.php/Revet/article/view/337 . Acesso em 30/II/202I.

BAHIA, M.; SILVA, J. S.; GONTIJO, I. S.; CORDEIRO, M. D.; SANTOS, P. N.; SILVA, C. B.; NICOLINO, R. R.; MOTA, D. A.; SILVA, J. B.; FONSECA, A. H. Caracterização da febre do carrapato bovino em bezerros da região noroeste de Minas Gerais, Brasil. Rev. Bras. Parasitol. Veterinario. vol.29 no.I Jaboticabal 2020 Epub o9 de abril de 2020. Disponível em: https://doi.org/10.1590/Sig84-2961202001I . Acesso em 30/II/2021.

BISPO, J. L. P.; ALMEIDA, E. C.; NUNES, D. M. Efeito do extrato bruto de jenipapo (Genipa americana) no controle do carrapato bovino Rhipicephalus (Boophilus) microplus; Research, Society and Development, v. 9, n. 9, e481997308, 2020. Disponível em: http://dx.doi.org/ro.33448/rsd-v9i9.7308 . Acesso em 30/II/2021. 
COELHO, M. D. G.; BARBOSA, L. F. M.; FRANCO, T. F.; AMEIDA, K. S.; AKISUE, G. Controle do ectoparasita de bovinos Rhipicephalus (Boophilus) microplus, através do uso de óleo essencial do Cravo da Índia (Syzygium aromaticum) e óleo de Neem (Azadirachta indica). Rev. Agr. Acad., v.2, n.4, Jul/Ago (2019). Disponível em: http://dx.doi.org/10.32406/v2n42019/203-210/agrariacad. Acesso em 30/II/2021.

CRUZ, B. C. Aspectos Ecológicos, Biológicos e de Resistência de Rhipicephalus (Boophilus) microplus (Acari: Ixodidae) na região de Jaboticabal, São Paulo, Brasil; Repositório Institucional UNESP. Publicado em 27/10/2017. Disponível em: http://hdl.handle.net/II449/I52282. Acesso em 30/II/2021.

FIGUEIREDO, C. H. A.; AlENCAR, M. C. B.; SOUZA, K. A.; PEDROZA, A. P.; SILVA, C. F.; RIBEIRO, S. R. S.; NETO, O. L. S.; ROBERTO, S. B. A. A Utilização Medicinal da Mentha spp. INTESA - Informativo Técnico do Semiárido (Pombal-PB), v Iо, $\mathrm{n} \quad 2, \quad \mathrm{p} \quad \mathrm{I} 6 \quad-\quad 20, \quad 2016 . \quad$ Disponível em: https://www.gvaa.com.br/revista/index.php/INTESA/article/viewFile/4555/3905 Acesso em 30/II/2021.

GAlli, G. M.; VOlPATO, V .; Santos, R. C. V.; GEBERT, R.R; QUATRIN, P.; OURIQUE, A. F.; KLEIN, B .; WAGNER, R .; TONNIN, A. A .; BALDISSERA, M. D. ; STEFANI, L. M.; SILVA, A. S. Effects of essential oil of Eucalyptus globulus loaded in nanoemulsions and in nanocapsules on reproduction of cattle tick (Rhipicephalus microplus) Arquivos de Zootecnia. 67 (260): 494-498. 2018. ISSN: ooo4-0592. Disponível em: https://www.uco.es/ucopress/az/index.php/az/article/view/3879/2288 . Acesso em $30 / \mathrm{II} / 2021$.

JAIME, E. M. Efeito do Extrato do Eucalyptus Globulus em fêmeas ingurgitadas de Rhipicephalus sanguineus. Curso de Medicina Veterinária - UNICEPLAC, 2019. Disponível em: https://dspace.uniceplac.edu.br/handle/I23456789/171 . Acesso em 30/II/2021.

MENDES, N. S. Ocorrência e diversidade genética de Babesia bovis em bovinos de corte amostrados no Pantanal Sul Matogrossense. Dissertação de Mestrado em Microbiologia 
Agropecuária. Jaboticabal: Universidade Estadual Paulista. Publicado em: or/o3/2019. Disponível em: http://hdl.handle.net/I1449/180975. Acesso em 30/II/2021.

MORAIS, P. G. S.; SILVA, M. C. A. S.; GONÇALVES, M. F.; AMBROSIO, A.; FAGUNDES, N. S.; NASCIMENTO, M. R. B. M. A influência da co-evolução bovinos/carrapatos nos métodos de controle e ambiência na bovinocultura. PUBVET, Londrina, V. 7, N. 9, Ed. 232, Art. 1534, 2013. Disponível em: https://www.pubvet.com.br/uploads/213eb52bobb5496fd3cc34362286a2b9.pdf . Acesso em $30 /$ II $/ 2021$.

NEPOMOCENO, T.A.R.; PIETROBON, A. J. A. Utilização de plantas medicinais no controle de carrapatos em bovinos leiteiros. Revista Científica Semana Acadêmica. Fortaleza, ano MMXVIII, №. ooorzo, 2018. Disponível em: https://semanaacademica.com.br/artigo/utilizacao-de-plantas-medicinais-no-controle-decarrapatos-em-bovinos-leiteiros. Acesso em 30/II/202I.

NEPOMOCENO, T.A.R.; PIETROBON, A. J. Melaleuca alternifolia: uma revisão sistemática da literatura brasileira. Rev. UNINGÁ Review, Maringá, v. 35, eRUR3409, 2020. ISSN 2178-2571. Disponível em: http://revista.uninga.br/index.php/uningareviews/article/view/3409 . Acesso em 30/II/202I.

OLIVEIRA, M. K. F; PEDRASSANI, D. Extrato hidroalcoólico de eucalipto, Eucalyptus dunnii, no controle do carrapato bovino, Rhipicephalus (Boophilus) microplus. Rev. Acad. Ciênc. Anim. 2017;15: 4I-48. Disponível em: https://www.researchgate.net/publication/318288207_Extrato_hidroalcoolico_de_eucalipto _Eucalyptus_dunnii_no_controle_do_carrapato_bovino_Rhipicephalus_Boophilus_microplu s/fulltext/596roc37a6fdccc9biogrb75/Extrat30/II/2021. 
PAES, J. B.; SOUZA, A. D.; LIMA, C. R.; SANTANA, G. M. Rendimento e características físicas dos Óleos de Nim (Azadirachta indica) e Mamona (Ricinus communis). Floresta $e$

Ambiente 22(I):134-139; 2015. Disponível em: http://dx.doi.org/10.1590/2179-8087.047513 . Acesso em 30/II/202I.

PROENÇA, P. L. F. Sistema nanocarreador de zeina para compostos bioativos (óleo de menta, cipermetrina, clorpirifós e amitraz) visando controle do carrapato bovino. Repositório Institucional UNESP. Publicado em 21.05.2018. Disponível em: http://hdl.handle.net/II449/I5446I . Acesso em 30/II/202I.

KESSLER, R.H.; SCHENK. M.A.M. Ed. Carrapato, tristeza parasitária e tripanossomose dos bovinos. Campo Grande: EMBRAPA-CNPGC, 1998. 157p. Disponível em: https://ainfo.cnptia.embrapa.br/digital/bitstream/item/r9607I/I/Carrapato-tristezaparasitaria.pdf . Acesso em 30/II/202I.

RAUBER, A. C.; LEANDRINI, J. A., MOURA, G. S., FRANZENER, G. Plantas medicinais de uso agropecuário pelas famílias agricultoras do Núcleo Luta Camponesa da Rede Ecovida de Agroecologia no estado do Paraná. Revista Verde 15:3 (2020) 274-283. ISSN $198 \mathrm{I}-8203$. Disponivel em: https://www.gvaa.com.br/revista/index.php/RVADS/article/view/7776 . Acesso em 30/II/2021.

SANTOS, G B.; GOMES, I. M.M.; SILVEIRA, J. A.G.; PIRES, L. C.S.R.; AZEVEDO, S. S.; ANTONElli, A. C.; RIBEIRO, M. F.B.; HORTA, M. C. Tristeza Parasitária em bovinos do semiárido pernambucano. Pesq. Vet. Bras. vol.37 no.I Rio de Janeiro Jan. 2017. Disponível em: https://doi.org/10.1590/Soroo-736X201700oroooor . Acesso em 30/II/2021. 
SCHOLL, D. C.; EMBERS, M. E.; CASKEY, J. R.; KAUSHAL, D.; MATHER, T. N.; BUCK, W. R.; MORICI, L. A.; PHILIPP, M. T. Efeitos imunomoduladores da saliva do carrapato nas células dérmicas expostas a Borrelia burgdorferi, o agente da doença de Lyme.

Parasitas e vetores, v. 9, 2016. I-I7 p. Disponível em: https://doi.org/Io.II86/sizo71-016-I6387. Acesso em 30/1I/2021.

SANTOS, S. F. A.; PAULINO, V. T.; KATIKI, L. M.; VERÍSSIMO, C. J. Perfil do produtor de leite da região de Joanópolis/SP: como ele lida com o controle do carrapato Rhipicephalus microplus e de outras doenças de importância veterinária. Pesq. Vet. Bras., Rio de Janeiro, v. 38, n. I, p. 77-88, 2018. Disponível em: http://dx.doi.org/10.159o/1678-5150-pvb4825 . Acesso em $30 /$ II $/ 2021$.

SILVA, T. F.; ALVES-SOBRINHO, A. V.; LIMA, L. F. S. de; ZIEMNICZAK, H. M.; FERRAZ, H. T.; LOPES, D. T.; SILVA, V. L. D. da.; BRAGA, Ísis A.; SATURNINO, K. C.; RAMOS, D. G. de S. Tristeza parasitária bovina: Revisão. Research, Society and

Development, [S. 1.], v. Io, n. I, p. er54Iorir631, 2021. Disponível em: https://rsdjournal.org/index.php/rsd/article/view/ri63I . Acesso em 30/II/2021.

SILVA, L. A. O uso de homeopatia e fitoterapia no controle de ectoparasitas no manejo sanitários de bovinos de leite. Universidade Federal da Fronteira Sul Campus Erechim. Pontão - RS. 2018. Disponível em: https://rd.uffs.edu.br/handle/prefix/2258 . Acesso em $30 /$ II $/ 2021$.

SILVA, L. M.; CALDAS, A. P.; RODRIGUES, A. L. M. R.; OLIVEIRA, J. S.; SIMONETTI, E. R. S. O uso do extrato de fumo (Nicotina Tabacum) como alternativa para o controle de pragas em hortaliças. $2^{-}$Congresso Internacional de ciências Agrárias COINTER - PDVAgro 2017. Disponível em: https://cointer-pdvagro.com.br/wpcontent/uploads/2018/o2/O-USO-DO-EXTRATO-DE-FUMO-Nicotina-tabacumCOMO-ALTERNATIVA-PARA-O-CONTROLE-DE-PRAGAS-EMHORTALI\%C3\%87AS.pdf . Acesso em 30/II/202I. 
SILVEIRA, W.H., CARVALHO, G.D.; PECONICK, A.P. Medidas de controle do carrapato Rhipicephalus microplus: uma breve revisão. PUBVET, Londrina, V. 8, N. io, Ed. 259,

Art. 1715, 2014. Disponível em: https://www.pubvet.com.br/artigo/1245/medidas-decontrole-do-carrapato-rhipicephalus-microplus-uma-breve-revisatildeo. Acesso em $30 /$ II $/ 2021$.

SEBOLD, W; GAI, V. F; Uso do óleo de Neem no controle de Boophilus microplus em bovinos leiteiros. Edição Especial 2017. p. I55 a I6I. I55 ISSN 2175-2214. Disponível em: https://www.fag.edu.br/revista/cultivando-o-saber/80.Acesso em 30/II/202I.

TURETA, E. F.; VARGAS, G. P.; FIORIO, M. S.; WORTMANN, B. B.; OLIVEIRA, L. R. S.; ROSA, R. L.; SOUZA, E. M.; SANTI, L.; SILVA, W. O. B. Métodos alternativos e sustentáveis de controle do carrapato bovino Rhipicephalus microplus. Revista Liberato: educação, ciência e tecnologia. Vol. 20, n. 34 (jan./jun. 2020), p. 27-37. Disponível em: http://hdl.handle.net/ror83/214380. Acesso em 30/II/202I. 